\title{
Translation in Literary Discourse: Distribution Approached from Localization I Localization Approached from Distribution in Literary Texts
}

\author{
Mohammad Reza Talebinejad \\ Islamic Azad University, Shahreza
}

\begin{abstract}
An important aspect of a text concerns its materiality. In more recent terminology used in defining texts, they are considered "objects" or "bearers" of messages. If this is taken seriously, texts must have some physical body that is able to move. This is where the idea of distribution can be presented. In the electronic age, texts move across the world in seconds. Are texts, then, moving in the sense that material things move? That is, do we in fact transfer the form or the meaning? Since the translator's responsibility is to change the form only while keeping the meaning constant, are we moving the text? This is the question the present paper puts forward and hopes to provide a possible answer to. To this end, the play Death of a Salesman by Arthur Miller was selected for analysis in terms of its adaptability for translation across cultures. The purpose was to see if in literary works localization can be achieved through distribution. The model for analysis was adapted from Anthony Pym (2004), along with the principles of the theory of relevance and the skopos theory. The analysis showed that from a cultural point of view the message is not moved through the text when adapted in translation into Persian.
\end{abstract}


Keywords: text adaptation, distribution, localization, discourse, translation

\section{Introduction}

There have been several attempts to find more recent ways of defining texts, especially in the past decade. Among these, three names have enjoyed more popularity among discourse researchers, namely "Information Objects" (Hofman \& Mehnert 2000); "Information Elements" (Lockwood 2000); and "Material" (Essenlink 2003). Pym (2004: 17) considers such definitions as "minor flings with new names," which he thinks "might be attributed to models of thought opened up by the electronic information of language strings."

Translated texts often betray their being 'transported' from another language. Professionals can even determine the SL from the weird phrases, strange or wrong word orders and other problems. Pym comes up with not-so-funny examples from the computer world, mentioning that the computer industry is just one among the many areas where the TL texts are often incompatible with the reader, culture and language. If they were, we could call them 'localized' texts. Localization must be preceded by active 'distribution' rather than "passive reproduction or adaptation" (2004: 5).

Translation is part of localization. True, but (good) translators and translation theorists all know that translation involves the transmission of the message retaining the source culture (and everything else) as much as needed and the conversion of the text to meet the requirements of the target language reader. This means that translation has always embedded exactly what Pym calls 'localization'. The hermeneutic circle - the question of part and whole-is revisited. And we need not get out of the circle. Good 
translators keep cooperating with the professionals if the text is of technical nature, and they are fiction writers and poets in the case of literary works. Localization is not achieved when the translator, thinking (s)he is omniscient, works in isolation.

A translator, just like an author, is not simply a 'person' but a socially and historically constituted subject. Translators interpret texts by setting them against their backdrop of known words and phrases, existing statements, familiar conventions, anterior texts, or, in other words, their general knowledge which is ideological. This knowledge allows them to interpret the text and at the same time limits the range of their interpretation.

What brings de facto the individual interpretations close together is the likeness of the intertextual and ideological configurations the individuals are located in. Translators are hardly (maybe never) aware of ideological factors governing their process of the source text interpretation.

While one of the pivotal achievements of the poststructuralist approaches is dethroning the author and his/her authorial intention by emphasizing the role of the translator as an autonomous reader of the source text, functionalist approaches try to dethrone the source text itself by emphasizing the role of the translator as a creator of the target text and giving priority to purpose (skopos) of producing target text.

The principles of translational (translatorial) action theory then founded the basis of Vermeer's Skopos theory. 'Skopos is a technical term for the aim or purpose of a translation' (Vermeer 2000: 221). Skopos theorists assert that any action has an aim, a purpose. From their standpoint, translation is considered not as a process of transcoding (the position usually adopted by earlier nonfunctionalist approaches), but as a form of human action which has its own purpose basically decided on by the translator (Hцnig 1998: 9). The skopos of a translation, Vermeer (2000: 229) explains, is the goal or purpose, defined by the commission and if necessary 
adjusted by the translator. He defines commission as "the instruction, given by oneself or by someone else, to carry out a given action," which could be translation.

The translator, as an expert in translational action, must interpret ST information "by selecting those features which most closely correspond to the requirements of the target situation" (Shuttleworth $\&$ Cowie 1997: 156). From this point of view, the translation process is not (necessarily) determined retrospectively by the source text, its effects on its addressees, or the intention of its author, but prospectively by the skopos of the target text as determined by the target recipient's requirements (which are, however, discerned and decided on by the translator himself / herself). The translation then is the production of a functionally appropriate target text based on an existing source text.

Focusing on the purpose of translation as the most decisive factor in translation action, skopos theory emphasizes the role of the translator as an expert in translational action and regards the source text no longer as the 'sacred original' from which the skopos (purpose) of the translation is deduced, but as a mere offer of information whose role in the action is to be decided by the translator, depending on the expectations and needs of the target readers (Hцnig, 1998: 9). Skopos theory and functionalism focus on the translator, giving him/her more freedom and at the same time more responsibility, as Hцnig (1998: 10) asserts:

[The translator] may be held responsible for the result of his/her translational acts by recipients and clients. In order to act responsibly, however, translators must be allowed the freedom to decide in co-operation with their clients what is in their best interests.

An awareness of the requirements of the skopos, Vermeer maintains, 'expands the possibilities of translation, increases the range of 
possible translation strategies, and releases the translator from the corset of an enforced - and hence often meaningless - literalness' (cited in Shuttleworth \& Cowie 1997: 156). Hцnig (1998: 14) usefully contrasts the characteristics of functional approaches vs. nonfunctional approaches as follows:

\begin{tabular}{|l|c|l|}
\hline \multicolumn{1}{|c|}{ Functionalist } & \multicolumn{1}{|c|}{ Non-Functionalist } \\
\hline $\begin{array}{l}\text { Is loyal to his client must } \\
\text { be visible }\end{array}$ & \multicolumn{1}{|c|}{ Translator } & $\begin{array}{l}\text { Faithful to the author } \\
\text { should be invisible }\end{array}$ \\
\hline Target text oriented & processes should be & Source text oriented \\
\hline $\begin{array}{l}\text { Communicative } \\
\text { acceptability }\end{array}$ & Aim of translation is & Linguistic equivalence \\
\hline $\begin{array}{l}\text { Psycho-, sociolinguistics, } \\
\text { text linguistics } \\
\text { (supporting decisions) }\end{array}$ & $\begin{array}{c}\text { Translation tools } \\
\text { taken from }\end{array}$ & $\begin{array}{l}\text { Contrastive linguistics } \\
\text { lexical semantics } \\
\text { (applying rules) }\end{array}$ \\
\hline Building bridge & Analogy & Crossing river \\
\hline
\end{tabular}

Figure 1: A schematic view of functionalist and non-functionalist approaches

As it is evident in Hцnig's schematic view, 'visibility' of the translator is a key concept in functional approaches. According to Hunig (1998: 12-13), in functionalism the translator inevitably has to be visible, since functional approaches do not establish rules but support decision-making strategies and the translator has to make critical decisions as to how define the translation skopos and which strategies can best meet the target recipient's requirements. $\mathrm{S} / \mathrm{He}$ should be visible, making his/her decisions transparent to his/her 
client and accepting the responsibility of his/her choices. A visible translator has to accept the consequences of his/her translational decisions, as Toury (1999: 19) declares, "t is always the translator herself or himself, as an autonomous individual, who decides how to behave, be that decision fully conscious or not. Whatever the degree of awareness, it is s/he who will also have to bear the consequences."

According to Nord (2003: 111), almost any decision in translation is - consciously or unconsciously - guided by ideological criteria. Ideological factors are very decisive in defining the translation skopos (target-text intended purpose) and selecting the functionally appropriate strategies by the translator, based on the expectations of the translation clients. These factors which affect and regulate the translator's behavior are further investigated in the following section under the title of 'norms'.

According to Toury, all human beings have an inherent tendency toward socializing and social acceptability; as a result, under normal conditions, people tend to avoid behaviors which are prohibited or sanctioned as well as to adopt behaviors which are considered as being appropriate within the group they belong to (1999: 15-19). There is a socially shared knowledge between members of every community as to what is considered correct or appropriate as a communicative behavior. This knowledge exists in the form of norms. They serve consciously as a pattern of behavior, and 'they also regulate expectations concerning both behavior itself and the products of this behavior. Toury (1999) defines norm in terms of 'the translation of general values or ideas shared by a group-as to what is conventionally right and wrong, adequate and inadequateinto performance instructions appropriate for and applicable to particular situations' (14). Taking into consideration the definition of ideology by van Dijk (1996) as 'the organized evaluative beliefs shared by social groups', norms -- as defined by Toury (1999) -seem to have much in common with ideology; in other words, norms can be understood as ideological realization of the concept of 
appropriateness and correctness.

Decision-making is a key concept in the discussion of norms. Norms exist 'only in situations which allow for alternative kind of behavior, involving the need to select among these, with the additional condition that selection be non-random' (Toury, 1999: 15). This selection, according to Toury, could be posited between two constraining extremes of 'relatively absolute rules on one hand, and pure idiosyncrasies on the other' (1999: 16).

Toury applies the norms concept to translation studies presuming that translating involves playing a social role subject to several types of socio-cultural constraints of varying degree. He, consequently, argues that the acquisition of a set of norms for determining the suitability of translational behavior, and for maneuvering between all factors which may constrain it, is a prerequisite for becoming a translator within a cultural environment (Toury 2000: 198).

Toury (2000) claims that norms govern every level of decisionmaking in the translating process from choice of text to translate to the very final choices of translation strategies of action. He, consequently, introduces three kinds of norm: 1) initial norm; 2) preliminary norms; and 3) operational norms.

Initial norm governs the translator's overall decisions to adhere 'either to the original text, with the norms it has realized, or to the norms active in the target culture, or in that section of it which would host the end product' (Toury 2000: 201). Toury (2000), however, denies the necessity of full conformity between an overall decision made and every single decision be made in the lower-levels of translation process; and, consequently, denies the existence of absolute regularity in translational behaviors. The options which are made available to the translator by Toury's initial norm are very similar to those which Venuti (1998: 240) talks about in his foreignizing and domesticating strategies of translation.

Preliminary norms govern the decisions to be made concerning translation policy and directness. According to Toury (2000: 202), 
'translation policy refers to those factors that govern the choice of text types; or individual texts, to be imported through translation into a particular culture/language at a particular point in time'. He further explains that 'considerations concerning directness of translation involve the threshold of tolerance for translating from languages other than the ultimate source language'.

Operational norms direct the actual decisions made during the act of translation and are subdivided into matricial and textuallinguistic norms. Matricial norms govern the segmentation and distribution of textual materials in the target text. Textual-linguistic norms 'govern the selection of material to formulate the target text in, or replace the original textual and linguistic material with' (Toury 2000: 202-3).

It should be noted that, according to Toury (2000), 'There is no necessary identity between the norms themselves and any formulation of them in language (200). He believes that the observed regularities in translational behaviors are not themselves the norms; they are rather 'external evidence' which reflect the existence of norms (Toury 1999: 15). Therefore, Baker's interpretation of norms as 'regularities of translational behavior within a specific sociocultural situation' (Baker 1998: 163) or 'strategies of translation which are repeatedly opted for, in preference to other available strategies, in a given culture or textual system' (in Shuttleworth \& Cowie 1997: 114) seems to be an oversimplification of this concept.

According to Toury (2000: 206), norms themselves actually are not observable. He declares that what are actually available for observation are rather norm-governed instances of behavior or the products of such behavior. Toury introduces two major sources for reconstruction of translational norms. The first is textual: the translated text themselves, for all kinds of norms, as well as analytical inventories of translation (i.e., 'virtual texts'), for various preliminary norms; and the other is extratextual: semi-theoretical or critical formulations such as perspective 'theories' of translation, 
statements made by translators, editors, publishers, and other persons involved in or connected with the activity, critical appraisals of individual translations, or the activity of a translator or 'school' of translators, and so forth (Toury 2000: 207).

Likewise, Baker (1998: 164) introduces studying of a 'corpus of authentic translations' as a means for identifying regular instances of translational behavior which are represented in that corpus by the translator, and, thus, for identifying the translational norms.

Kenesei (2007) wonders whether when the receivers treat a text as original can we say: 1) thatlocalization is successful and 2) that it does not imply a second person? For this reason Kenesei seems to disagree with what Pym (2004: 80) says, i.e., that "translation turns the world of persons into a world of things."

\section{Statement of the Problem}

From the discussion above, one can conclude that there is not agreement on what is possible to distribute, localize or globalize. The hypothesis put forward in this respect will therefore have to be one that embraces not only the act of text adaptation but also translation in that this way both views will be taken into consideration. What seems to be the problem now is that we cannot know exactly what the production systematically meant. What we can recognize, however, is that there was meaningful materiality. The test here, therefore, is of the extent to which that meaning, as understood in the original work, is distributed in the act of translation. One area which does not easily lend itself to translation is the area of cultural issues, specifically symbols and metaphors in any language. If one can show that metaphors and symbols are only distributed to the point that their universality allows, then it can be safely concluded that localization is possible through translation too.

The aim of the present paper is to show some of the problems 
which arise when the translator decides to localize a text. For this purpose, the Persian translation of Arthur Miller's Death of a Salesman was analyzed with the following points in mind:

1. To what extent is symbolism in the original work adapted in the Persian translation?

2. To what extent does the translator succeed in localizing the many metaphors employed by the original writer?

3. Is the playwright's attempt to picture a social system nullified or in any way promoted in the translation?

And of the many symbols, metaphors, images and analogies used in the original dram, the following were selected for analysis: the title of the play, the music heard in the play, the name of the characters, the social values prevalent at the time the play was written

\section{Model for Analysis}

The model for analysis was adapted from Pym's (2004) principles as elaborated in the following principles. (1) The textual worlds overcome resistance to distribution; therefore, the more a text is explicit and codified within its own world, the easier it is to distribute and the weaker is its belonging to an original I-here-now. (2) the use of local variants can have a performative effect, resisting distribution by creating implicit knowledge. The movement of such texts may require extreme explication, creating textual worlds through the use of narrative. (3) Belonging means that the specific referents of many terms remain vague even in their source locales, creating significant indeterminism even before the moment of distribution to another locale. (4) Natural languages strongly reinforce relations of belonging because they bind together experience in many different fields, and do so by discursively 
structuring the subject. (5) Natural languages use terms in many different locales, and thus embed language within cultural complexes. This embedding resists distribution. In addition, van Dijk's (1979) psychological process model for relevance will be taken into consideration in the analysis. A short account of the model follows:

1. level of semantic analysis

2. categories, units or structures

3. surface structures

4. components of the cognitive set of the reader/listener

5. contextual relevance

6. textual relevance

7. interaction between textual and contextual relevance

\section{Procedure}

The present study intends to look at each significant feature in the play listed above and highlight the points that need to be considered in terms of being distributed, resistant to distribution, localized, not localize-able, or neutralized either on purpose or ignored since the translator did not find a relevant way to express the idea in Persian.

The title of the play is the first point of conflict in that the term salesman is reduced to a term in Persian (FOROOSHANDEH) which is neutral, compared with its counterpart in English which has the connotative meaning of being insignificant. The question is why death of a salesman and not of a manager, or even a coordinator? There is something in the term itself that serves the purpose. This, however, is missing in the Persian title. If you take the following as a basis for the cultural significance of the death of people, then you'll see why the Persian title is not suggestive enough: 


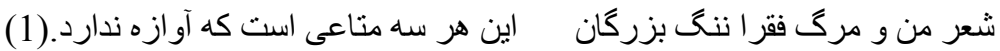

Shear mano marg foghar nange bozorgan / een har se mataaist ke avaze nadarad!

Poetry of mine, death of the poor, scandal of the rich: / these three things have no echo!

The term man (me) in the Persian version makes all the difference, not the term death. A salesman can be any person who sells goods. But Willy Loman is just an ordinary man. He belongs to the low level society. His death, therefore, should not be significant, as signaled by the title. FOROOSHANDEH, even when followed by the modifier DOWREGARD (going from door to door) in some translations which have recognized this connotative meaning, is still inadequate in expressing the insignificance of the person in Miller's original work. Persian does have a term, though, which is to some extent connotatively similar to what Miller had in mind, i.e. DASTFOROOSH (peddler). But the question is why didn't Miller use the term peddler instead of salesman? This is where the problem put forward in the introduction reappears: We do not know what the original production meant! Or did we?

From a historical point of view, the play is a cry against the social values being promoted by the American system at that time. The American Dream does not tolerate concerns with low class people since the system is based on survival of the fittest. In systems where this idea is not a real issue, as in the religiously or politically oriented societies, this may be hard to either digest or tolerate. Adaptation of an idea like this is, therefore, easy in the sense that it is not far from the minds of people and lends itself to conversion to the language of the target culture. However, it is difficult to interpret for the audience in the target language since it is not what people usually have or feel as their daily problem. People of all walks of life die in similar fashions and there is not much difference between the ways they are remembered afterwards, except for what they have 
themselves achieved in their life. In the system Miller had in mind, however, things were different. You had to be somebody to be revered in your life or remembered after you die. Death of $a$ salesman, therefore, is as significant as the disappearance of a fly from the surface of the earth in a society with such values! The message intended by the original writer, then, is not localized in any way in its Persian translation.

The next symbol which needs explaining in terms of adaptability is the music played on the flute. The flute is similar both in structure and sound to the reed (pipe), or NEY in Persian music. The effect is much the same except for the fact that the flute has a lot more variety in being tuned to the western type of music. The $N E Y$ is usually employed in providing a sense of nostalgia and dramatic effect in loneliness. This instrument is believed to have been attributed to Adam's expulsion from heaven and his separation from God. In Persian mystic poetry, the $N E Y$ is very much popular and appears in many verses where people refer to man's loneliness on the earth. The most famous verse, also the origin of this, is Molavi's:

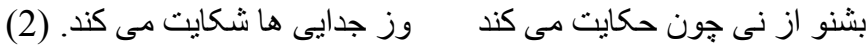

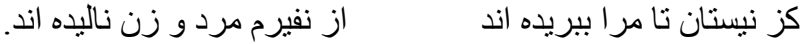

Beshno az ney choon hekayat mikonad / vaz jodayeeha shekayat mikonad Kaz neyestan ta mara bobridaand / az nafiram mardo zan nalidaand

Listen to the NEY when it talks / and complains about being separated

Since the time I was detached from the origin / people have been crying with my music.

In mystic poetry, this is quite a well-known symbol and any Persian speaker will appreciate the symbolic meaning of the instrument. Shepherds usually carry a $N E Y$ to play while alone with their cattle in the grassland. Some other uses of the NEY are in 
mourning ceremonies or religious rituals where the theme is separation from something one loves or is nostalgic about.

In this sense, therefore, the sound of music is quite natural to be adapted as it is but the tuning differs greatly in the two cultures. More specifically, the NEY plays the music of sadness, like that in mourning, while the flute is very much for romantic sadness, or nostalgia.

The names in the play are all symbolically used to represent some aspects of the characters of the play. They would be difficult if not impossible to replace with either Persian names with the same effect or to transfer the same effect using the English names in Persian.

To start with, there is the name of the main character, i.e. Willy Loman which is not very difficult to decode, given the homophony of Loman with low man, a man from the lower level of the capitalist society appearing at the time when the play was written. We can safely conclude that Miller did have this in mind when he wrote the play. How could we transfer this obvious use of linguistic trick to Persian? The answer is not a yes/no one. This is one good example of a case where texts will have to be glocalized, to use the term employed by Pym and others in combining globalization and localization in one sense. There are two aspects of this linguistic device which need adaptation: The first name Willy denoting triviality when used for an adult of that age; and the surname which as mentioned is obviously a linguistic device to express an opinion by the playwright. The evidence for that is that Willy is William for his loyal wife but rarely anybody else calls him William.

In transferring names, the translations into Persian have chosen to ignore this fact and suffice with some explanatory notes here and there to refer to Willy's life in which they have tried to somehow include this point. However, the effect is not at all comparable to that made in the original. Culturally, Persian can be used in expressing such denotative expressions by adding a suffix such as 
ie or ee sound to the name as in Hassanee, and Willie (pronounced as willie or willyee). This however, sounds unnatural in English and will, of course, be both inadequate and funny in Persian without making the effect Willy produces in English.

The other name which is ironically used in the play but has not been localized in Persian, is Happy. Is Happy really happy in life? The answer to this question is only the concern of this study as far as it relates to the choice made by Miller. No, he is not. There is abundant evidence in the play that he is not. Why does Miller, then, choose to call him Happy? Again the social situation Happy lives in explains it. Happy has learned to have a good time because his father thinks he is an Adonesis. He does everything in his power to look happy, even if it is by pretending to be so. His moral obligations do not keep him from ruining others' life, like the time he confesses to ruining several girls on the eve of their marriages. He is by no means a happy young man. The Persian translation fails to give a hint to this ironic use of the name and just treats as a name. Is this possible in Persian? Yes, it is but it needs some initiative! For instance, in Persian we have cases where names are the opposites of the their owners, either physically or in terms of their characters:

بر عكس نهند نام زنكى كافور ! (3)

Bar aks nahand name zangi kafoor

In reverse, they name a Negro Camphor!

This type of sarcastic or symbolic names abound in Persian. Some other cases are names such as einollah (God's eye) used for people with eyes either not so beautiful or even blind, and zolfali (a man with long hair) for bald people.

The next significant name in the play is Biff. He was a star football player in high school, with scholarships to two major universities. He flunked math his senior year and was not allowed to 
graduate. He was going to make the credit up during the summer but caught Willy being unfaithful to Linda. This shock changed Biff's view of his father and everything that Biff believed in. Biff then became a drifter and was lost for fifteen years. He was even jailed for stealing a suit once. But now, he has come home and the problems begin.

Willy wants dearly for Biff to become a business success, although Biff has an internal struggle between pleasing his father and doing what he feels is right. Biff wants to be outside on a cattle ranch, and Willy wants him behind a corporate desk. Through the illusions that Willy believes, he cannot see that Biff is a nobody and not bound to be successful as defined by Willy. This conflict is the main material of the play.

Once outraged, Willy shouts, "I am not a dime a dozen! I am Willy Loman and you are Biff Loman!" But Biff is destined to no greatness. The name, then, may be symbolically interpreted to mean what he himself realizes, though late: a "dime a dozen" and "no great leader of men." Could the translator have done differently here by finding a name more appropriate to fit a person like Biff? The answer is not readily yes or no. Do we need more theoretical information to decide? Obviously yes, but that alone won't do either. A more relevant choice of names in this regard would depend more on a deeper conceptual knowledge of the target text. This is one major reason for the need to investigate the cultural norms of the source language in which the text has been produced in the first place.

Linda is Willy's wife and is the arbiter of peace in the family. She is always trying to stand between Willy and her sons to ease the tension. She is protective of Willy. She knows that Willy is tired and is a man at the end of his rope at the end of his life and, as he put it, "ringing up a zero." She wants him to be happy even when the reality of the situation is bad. Linda knows that Willy has been trying to commit suicide, but does not intervene because she does 
not want to embarrass him. She lets it continue because she is not one to cause trouble. All these positive characteristics remind us of a name which should naturally fit her, Linda! Doesn't she link the broken parts of the family? How do we understand this concept in Persian? Although there is no name which carries this bundle of meanings in either language, the translator could have tried adding some kind of an attribute to it to make it closer in its connotative meaning. In Persian this could be a title such as maman, especially if added after the name, thus Linda maman!

There are also minor characters in the play whose names do not carry significant ironic or symbolic values. However, the names have been chosen to represent the ideas related with the American Dream, the theme of the play. Among them, Charlie, who is the Loman's next door neighbor, and owns his own sales firm. He and Willy do not get along very well, but they are friends nonetheless. Charlie is always the voice of reality in the play, trying to set Willy straight on the facts of Willy's situation, but Willy refuses to listen. The name fits him well in the context of the play and one can hardly try to replace with a Persian name of that relevance.

Bernard is Charlie's goody-two-shoes son who was a childhood friends of Biff. Bernard always studied and eventually became a successful lawyer, something that Willy has trouble dealing with. The name is one with no significant symbolic value and therefore does not create any problem here.

Ben is Willy's dead brother who appears to Willy during his flashbacks and times of trouble. Ben was a rich man who made it big in the diamond mines of Africa. Willy once was given the chance to become partners with Ben, but refused and instead choose the life that he currently lives. The name, especially when used by Biff and Happy, rings a bell. Uncle Ben! Nevertheless, it is not easily replaceable with a Persian name to serve the same function.

The symbols which abound in the work include names of characters as well as places or objects used in the play. Some of the 


\section{Translation in Literary Discourse}

significant symbols will be pointed out here to show the problems a translator faces in the process of adaptation. Willy symbolizes the common man, as discussed earlier. This symbolism is not appropriately present in the Persian translation since the tone of the drama is not easily adaptable in Persian. This could have political as well as ideological explanations which are not in order here. Biff's football game represents a symbol of success for the future to Willy, in a society which is more like a football field or wrestling arena than a real social community where people live together, not compete with each other. Ben represents all that Willy wishes the boys to be, yet his actions in the past are not firmly established. He is, for Willy, a symbol of all that is "good in the land of opportunity." The garden is symbolic of Willy needing to leave something behind for people to remember him by. It also represents the temporary hope he has about his son's success, which is, alas, lost in the end.

Have these symbols been adapted properly in Persian? It seems that at the time the play was translated, such literary devices were not the concern of the people who worked in the filed. They were mostly, at times solely, focused on transferring the semantic meaning rather than the conceptual meaning of the text. This could be considered the main reason for the inappropriate translations made in Persian in the majority of works adapted in this way. However, there are literary works, alas very few, which have been adapted in Persian with little translator visibility. These are specifically those masterpieces translated by literary figures who were not only familiar with the stylistic features of the texts they adapted but also with the concepts behind them. Examples are Shakespeare's plays in Persian by Saeed Nafisi, a great modern Persian writer and translator which is now recognized as a classical piece of literary translation in Persian.

Why does that happen? The answer lies in the explanations that the Skopos theory of translation might provide: Much of what we do 
in translation depends on the purpose of the translator. Perhaps at the time the play was translated into Persian there was little information about such views as the theory of relevance or the Skopos theory. This is what has in fact rendered most of the translated works of the past masterpieces to what we see as personal choice of the great translators of the past, those who had little theoretical knowledge of translation but were experts in both languages. However, from the perspective of today's researchers of translation, a major concern is the theoretical framework within which they work, while the knowledge of language itself is sometimes inadequate. Both parties need to look back at what they have done or are doing with open eyes. In retrospect, we find the subjectivity in the works of great translators more effective than the theory-based works of the present day translators who seem not to see the woods for the trees!

\section{Conclusion}

Much of what has been expressed in the form of translation in the Persian version of the drama Death of a Salesman can be readily understood and to a great extent even appreciated, thus the several stage versions of it in Persian. However, there are many aspects of the drama which have not rendered themselves to translation and have either been reduced to zero translation, or have remained to be followed only by the elites who are already familiar with the original and its implications.

The principles in Pym's model mentioned earlier then seem to be at work in the present study of the play Death of a Salesman, normally considered a literary piece of work in the modern sense of it. That is, each principle seems to make sense when considered in the context of the translated work in question.

Textual worlds overcome resistance to distribution; therefore, the 
more a text is explicit and codified within its own world, the easier it is to distribute and the weaker is its belonging to an original I-herenow. The flashbacks to Willy's youth and how he failed and Ben made it, i.e., the jungle metaphor in Death of a Salesman are good examples of such resistance.

The use of local variants can have a performative effect, resisting distribution by creating implicit knowledge. The movement of such texts may require extreme explication, creating textual worlds through the use of narrative. The name symbols in Death of a Salesman are good examples of such resistance.

Belonging means that the specific referents of many terms remain vague even in their source locales, creating significant indeterminism even before the moment of distribution to another locale. The car brand, the way it is simonized and the way Willy and sons adore it and enjoy looking at it all could be compared with what it means in heir life then and later. This does not let itself to interpretation easily, nor can it be easily distributed in translation. What we gather from the Persian translation is hardly the effect intended in the original.

Natural languages strongly reinforce relations of belonging because they bind together experience in many different fields, and do so by discursively structuring the subject. American experience as represented in the type of structures, specifically in the genre selected for transferring the message in the play, is in fact not very tangible in Persian. Drama is not what the ordinary audience would appreciate in Persian, let alone a translation of it.

Natural languages use terms in many different locales, and thus embed language within cultural complexes. This embedding resists distribution. The cultural references that abound in the play mostly reflecting the American Dream are embedded in the language by imagery and irony, like that of Adonesis for the beautiful bodies Biff and Happy enjoy, as imagined by Willy, resist distribution without explanation. Explanation in this type of genre disrupts the flow of 
the work. Footnotes will help but then the naturalness of the language will still be an issue.

In this sense, the present author is of the opinion that the translation of Death of a Salesman in Persian has not really served the purpose of localization. But the question is whether it is expected to do so? The suggestion is that in literary works, what is necessary is globalization, rather than localization. Localization seems to fit general works with more materiality of information in mind than the aesthetic aspect of the text in question. In Death of a Salesman, the translation can be approached from a translation for globalization or distribution type, rather than a glocalization approach. There are a number of reasons this may be true among which the most outstanding is the genre type which resists distribution.

\section{References}

Baker, M. 1998. Norms. In M. Baker (ed.), Routledge Encyclopedia of Translation Studies 163-165. London: Routledge.

Essenlink, B. 2003. The Changing Face of Content Changes the Face of Translation. Proceeding of the 2003 Translation and Globalization Conference 29-31.

Hofman, C \& Mehnert. T. 2000. Multilingual Information Management at Schneider Automation. In R. Sprung (ed.), Translating into Success: Cutting-edge Strategies for Going Multilingual in a Global Age 59-79. Amsterdam: John Benjamins.

Hцnig, H. 1998. Positions, Power and Practice: Functionalist

Approaches and Translation Quality Assessment. In C. Schдffner (ed.), Translation and Quality 6-34. Philadelphia, PA: Multilingual Matters.

Lockwood, R. 2000. Machine Translation and Controlled Authoring 
at Caterpillar. In R. Sprung (ed.), Translating into Success: Cutting-edge Strategies for Going Multilingual in a Global Age 187-202. Amsterdam : John Benjamins.

Miller, A. 1949. Death of a Salesman. New York: Viking Press. . 2002. Marg Foroushande [Death of a Salesman] (A. Nourian, Trans.). New York: Viking Press.

Nord, C. 2003. Function and Loyalty in Bible Translation. In M. Calzada-Pйrez (ed.), Apropos of Ideology 89-112. Manchester: St. Jerome.

Pym, A. 2004. The Moving Text: Localization, Translation, and Distribution. Amsterdam: JBP Company.

Shuttleworth, M. \& Cowie, M. 1997. Dictionary of Translation Studies. Manchester: St. Jerome.

Toury, G. 2000. The Nature and Role of Norms in Translation. In L.

Venuti (ed.), The Translation Studies Reader 198-211. London: Routledge.

1999. A Handful of Paragraphs on 'Translation' and 'Norms'. In C. Schдffner (ed.), Translation and Norms, 9-31. Philadelphia, PA: Multilingual Matters.

Van Dijk, T. 1979. Relevance Assignment in Discourse Comprehension. Discourse Processes 2, 113-126. . 1996. Discourse, Opinions and Ideologies. In C. Schдffner \& H. Holmes (eds.), Discourse and Ideologies 7-37. Clevedon: Multilingual Matters.

Venuti, L. 1998. Strategies of Translation. In M. Baker (ed.), Routledge Encyclopedia of Translation Studies 240-244. London: Routledge. Vermeer, H. 2000. Skopos and Commission in Translational Action (A. Chesterman, Trans.). In L. Venuti (ed.), The Translation Studies Reader 221-232. London: Routledge. 